\title{
Front Matter: Volume 10850
}

, "Front Matter: Volume 10850," Proc. SPIE 10850, Ocean Optics and Information Technology, 1085001 (12 December 2018); doi:

$10.1117 / 12.2521725$

SDIE Event: International Symposium on Optoelectronic Technology and

SPIE. Application 2018, 2018, Beijing, China 


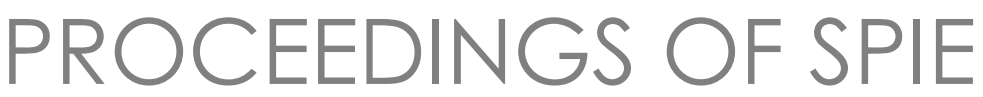

\title{
Ocean Optics and Information Technology
}

\author{
Xuelong li \\ Lixin Wu \\ Jianquan Yao \\ Hao Yin \\ Renhe Zhang \\ Zhongliang Zhu \\ Editors
}

22-24 May 2018

Beijing, China

Organized by

Chinese Society for Optical Engineering (CSOE) (China)

Photoelectronic Technology Committee, Chinese Society of Astronautics (China)

Photoelectronic Industrialization Committee, CHIA (China)

Department of Cooperation and Coordination for Industry, Academe and Research, CHIA (China)

Science and Technology on Low-light-level Night Vision Laboratory (China)

Sponsored by

Division of Information and Electronic Engineering of Chinese Academy of Engineering (China) Chinese Society for Optical Engineering (CSOE) (China)

Published by

SPIE

Volume 10850 
The papers in this volume were part of the technical conference cited on the cover and title page. Papers were selected and subject to review by the editors and conference program committee. Some conference presentations may not be available for publication. Additional papers and presentation recordings may be available online in the SPIE Digital Library at SPIEDigitalLibrary.org.

The papers reflect the work and thoughts of the authors and are published herein as submitted. The publisher is not responsible for the validity of the information or for any outcomes resulting from reliance thereon.

Please use the following format to cite material from these proceedings:

Author(s), "Title of Paper," in Ocean Optics and Information Technology, edited by

Xuelong Li, Lixin Wu, Jianquan Yao, Hao Yin, Renhe Zhang, Zhongliang Zhu, Proceedings of SPIE Vol. 10850 (SPIE, Bellingham, WA, 2018) Seven-digit Article CID Number.

ISSN: 0277-786X

ISSN: 1996-756X (electronic)

ISBN: 9781510623422

ISBN: 9781510623439 (electronic)

Published by

SPIE

P.O. Box 10, Bellingham, Washington 98227-0010 USA

Telephone +1 3606763290 (Pacific Time) · Fax +1 3606471445

SPIE.org

Copyright (C) 2018, Society of Photo-Optical Instrumentation Engineers.

Copying of material in this book for internal or personal use, or for the internal or personal use of specific clients, beyond the fair use provisions granted by the U.S. Copyright Law is authorized by SPIE subject to payment of copying fees. The Transactional Reporting Service base fee for this volume is $\$ 18.00$ per article (or portion thereof), which should be paid directly to the Copyright Clearance Center (CCC), 222 Rosewood Drive, Danvers, MA 01923. Payment may also be made electronically through CCC Online at copyright.com. Other copying for republication, resale, advertising or promotion, or any form of systematic or multiple reproduction of any material in this book is prohibited except with permission in writing from the publisher. The CCC fee code is 0277$786 \mathrm{X} / 18 / \$ 18.00$.

Printed in the United States of America.

Publication of record for individual papers is online in the SPIE Digital Library.

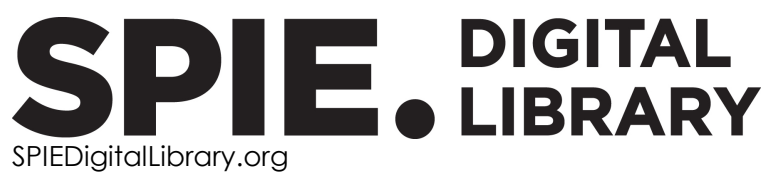

Paper Numbering: Proceedings of SPIE follow an e-First publication model. A unique citation identifier (CID) number is assigned to each article at the time of publication. Utilization of CIDs allows articles to be fully citable as soon as they are published online, and connects the same identifier to all online and print versions of the publication. SPIE uses a seven-digit CID article numbering system structured as follows:

- The first five digits correspond to the SPIE volume number.

- The last two digits indicate publication order within the volume using a Base 36 numbering system employing both numerals and letters. These two-number sets start with $00,01,02,03,04$, 05, 06, 07, 08, 09, 0A, OB ... 0Z, followed by 10-1Z, 20-2Z, etc. The CID Number appears on each page of the manuscript. 


\section{Contents}

$\begin{array}{ll}\text { vii } & \text { Authors } \\ \text { ix } & \text { Conference Committee } \\ \text { xi } & \text { Introduction }\end{array}$

OCEAN OPTICS AND INFORMATION TECHNOLOGY

1085002 Construction and application of ocean big data platform based on UAV system [10850-1]

1085003 Comparing approaches of suppressing tow ship noise with a horizontal line array [10850-3]

1085004 Research on the high-precision acoustic autonomous navigation technique of UUV based on sound ray revision [10850-4]

1085005 Test method of 1553b bus based on real airborne environment [10850-6]

1085006 Investigation of laser impulse broadening of breaking wave by the Monte Carlo method [10850-7]

1085007 Research on Mach-Zehnder interference sensors based on the fused tapered optical fiber technology [10850-10]

1085008 Research of nitrate concentration prediction based on GA [10850-11]

1085009 Development of automated observation radiometer for water-leaving radiance [10850-12]

$10850 \mathrm{OA} \quad$ Micro quasi-Michelson interferometric fiber optics hydrophone based on refractive index modulation [10850-13]

$10850 \mathrm{OB} \quad$ Variations in the optical backscattering properties of phytoplankton of different cell sizes [10850-14]

10850 OC Analysis of submarine optical cable eavesdropping defense means [10850-15]

10850 OD 3D information extraction algorithm of underwater target based on spatial mapping [10850-16]

$10850 \mathrm{OE}$ Research and development of applications of the theory of polarization aberration [10850-17]

10850 OF Underwater 3D reconstruction based on multi-view stereo [10850-18] 
10850 OG Underwater target recognition algorithm under the influence of non-uniform illumination [10850-19]

$10850 \mathrm{OH} \quad$ Simultaneous retrieval of aerosol optical thickness and exponent of Junge power-law from AATSR L1B [10850-21]

$10850 \mathrm{Ol} \quad$ The mobile sensor nodes scheduling algorithm based on grid competition in UWSNs [10850-22]

$10850 \mathrm{~J} \quad$ Evaluation method of Coastal Zone Imager performance based on remote sensing data analysis [10850-24]

10850 OK Marine local communication technology based on solar-blind ultraviolet [10850-26]

10850 OM A low frequency denoising algorithm of optical fiber laser hydrophone based on wavelet transformation [10850-30]

$10850 \mathrm{ON} \quad$ An underwater binocular vision positioning method based on back-propagation neural networks [10850-31]

1085000 Field experimental studies of detecting the dissolved $\mathrm{CO}_{2} / \mathrm{HCO}_{3}^{-}$using Raman spectroscopy [10850-32]

10850 OP Spatial variation of CDOM and its influencing factors in tropical East Indian Ocean during summer [10850-33]

$10850 \mathrm{OQ} \quad$ Experimental study on underwater range-gated imaging system pulse and gate control coordination strategy [10850-34]

10850 OR Comparison experiment of sun glint correction method for nearshore high-resolution multispectral satellite images [10850-36]

10850 OS An approach for sensing underwater particles using digital holographic imaging [10850-37]

10850 ОТ Monte Carlo simulation of radiative transfer in polarized spherically coupled ocean-atmosphere system [10850-41]

$10850 \mathrm{OU} \quad$ Simulations and measurements of polarization states changing in underwater laser transmission [10850-42]

10850 OV Miniaturized in situ dark-field microscope for in situ detecting plankton [10850-43]

10850 OW Marine plankton microscope system based on light field camera [10850-44]

10850 0X Remote sensing inversion of total suspended matter concentration in Oujiang River based on Landsat-8/OLI [10850-45]

10850 OY Spectral characteristics of Sargassum horneri in seawater [10850-46]

$108500 Z$ The deep-sea lamp design based on the light attenuation in water [10850-47] 
$1085010 \quad$ Underwater 3D imaging by a structured light system [10850-50]

1085011 The research on Modulation Transfer Function of underwater imaging system based on edge method [10850-51]

1085014 In-site chlorophyll-a fluorometer based on lock-in amplifier [10850-28]

Proc. of SPIE Vol. $108501085001-5$

Downloaded From: https://www.spiedigitallibrary.org/conference-proceedings-of-spie on 26 Apr 2023 Terms of Use: https://www.spiedigitallibrary.org/terms-of-use 
Proc. of SPIE Vol. $108501085001-6$

Downloaded From: https://www.spiedigitallibrary.org/conference-proceedings-of-spie on 26 Apr 2023 Terms of Use: https://www.spiedigitallibrary.org/terms-of-use 


\title{
Authors
}

Numbers in the index correspond to the last two digits of the seven-digit citation identifier (CID) article numbering system used in Proceedings of SPIE. The first five digits reflect the volume number. Base 36 numbering is employed for the last two digits and indicates the order of articles within the volume. Numbers start with 00, 01, 02, 03, 04, 05, 06, 07, 08, 09, OA, OB...0Z, followed by 10-1Z, 20-2Z, etc.

\author{
Bai, Yan, OY \\ Bao, Menglin, OY \\ Bi, Da-yong, OP \\ Cai, Wencai, OT \\ Cai, Xiao-qing, OP \\ Chen, Ming, $\mathrm{OZ}$ \\ Chen, Sheng-li, 09 \\ Chen, Xiang-zi, OZ \\ Chen, Xuyang, OD, OG \\ Chen, Yanlong, OB \\ Cheng, Chen, $\mathrm{OH}$ \\ Cheng, Xuemin, OE \\ Chu, Mengru, OR \\ Chu, Xinbo, OK \\ Ding, Yuan-ming, $\mathrm{Ol}$ \\ Fan, Chuanyu, $\mathrm{OH}$ \\ Fan, Yao, 08 \\ Feng, Jia, 03 \\ Feng, Lei, ON \\ Feng, Siyuan, 05 \\ Fu, Jin, 04 \\ Gan, Hui, 05 \\ Gao, Jian, ON \\ Gao, Ya, 14 \\ Gong, Fang, OT, OX, OY \\ Gu, Feifei, OF, 10 \\ Guan, Xiawei, OG \\ Guo, Jinjia, 00 \\ Guo, Buyu, OU, OV, OW \\ Guo, Xiangyu, OB \\ Han, Bing, OJ \\ Hao, Ge-yang, OM, OQ \\ $\mathrm{He}$, Xianqiang, OT, OX \\ He, Yuyao, OD, OG \\ Hou, Rui, OU, OV, OW \\ $\mathrm{Hu}$, Bingliang, 08 \\ Hu, Yingtian, OS, 14 \\ Huang, Shulan, OF \\ Huang, Xiaoguang, OY \\ Huo, Yi Wei, 06 \\ Ji, Chunhen, OK \\ Jia, Di, OJ \\ Jiang, Lingling, $\mathrm{OB}$ \\ Jiao, Zhiyong, 11 \\ Jin, Dongdong, OK \\ Li, Baoqi, OD, OG \\ Li, Chen, ON \\ Li, Dailin, 11 \\ Li, Guilei, 11
}

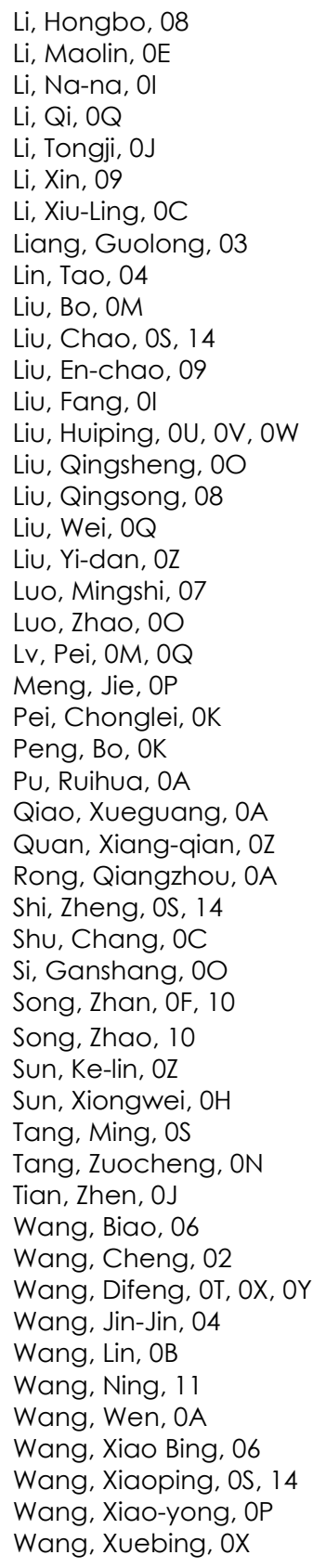


Wang, Xueji, 08

Wang, Yan, 03

Wang, Ying-Jian, $O C$

Wu, Guo-jun, OM, OQ

Xiang, Wang, OB

Xing, Yi, 11

$X u$, Gang, 05

$X u, P e i, O F$

$\mathrm{Xu}$, Qingshan, $\mathrm{OH}$

Xu, Shichao, 07

Xu, Wenbin, OU, OV, OW

Yan, Dong, 02

Yan, Wei, 05

Yang, Dan, 11

Yang, Dewang, 00

Yang, Lei, $\mathrm{OH}$

Yang, Yahan, OM

Yang, Yang, $\mathrm{OI}$

You, Xiangrong, 02

Yu, Jia, OU, OV, OW

Yu, Jiewei, OE

Yu, Tao, 08

Yuan, Guang, OU

Zhang, Gaopeng, OF

Zhang, Guang-Pu, 04

Zhang, Hai-long, $\mathrm{OZ}$

Zhang, Huaguo, OR

Zhang, Ran, $\mathrm{Ol}$

Zhao, Juan, OF, 10

Zhao, Yaohua, OD, OG

Zheng, Bing, OV

Zheng, Liang, $\mathrm{OC}$

Zheng, Ronger, 00

Zhou, Naien, 02

Zhou, Qing-wei, OP

Zhu, Huafeng, 11

Zhu, Jianhua, OJ

Zhu, Lin, $\mathrm{OH}$

Zhu, Ling Xuan, 06

Zhu, Qiankun, OT

Zhu, Yuhu, 05

Zong, Ruiliang, OD

Zou, Nan, 03 


\title{
Conference Committee
}

\author{
Conference Chair \\ Guangjun Zhang, Southeast University (China)
}

\section{Conference Co-chairs}

Junhao Chu, Shanghai Institute of Technical Physics (China)

Qionghai Dai, Tsinghua University (China)

Dianyuan Fan, Shenzhen University (China)

Jiancheng Fang, Beihang University (China)

Gu Min, Royal Melbourne Institute of Technology University (Australia)

Desheng Jiang, Wuhan University of Technology (China)

Huilin Jiang, Changchun University of Science and Technology (China)

Lin Li, The University of Manchester (United Kingdom)

Yueguang Lv, Chinese Academy of Engineering (China)

Zhejin Liu, National University of Defense Technology (China)

Wang Xiaomo, China Academy of Electronics and Information Technology (China)

Huaming Wang, Beihang University (China)

Lijun Wang, Changchun Institute of Optics, Fine Mechanics and Physics (China)

Wei Wang, China Aerospace Science and Technology Corporation (China)

Jianyu Wang, Shanghai Branch of Chinese Academy of Sciences (China)

Zuyan Xu, The Technical Institute of Physics and Chemistry (China)

Jiubin Tan, Harbin Institute of Technology (China)

Jianquan Yao, Tianjin University (China)

Hao Yin, China Electronic Systems Engineering Corporation (China)

Shaohua Yu, Wuhan Research Institute of Posts and Telecommunications (China)

Renhe Zhang, Institute of Acoustics (China)

Zisen Zhao, Wuhan Research Institute of Posts and Telecommunications (China)

Liwei Zhou, Beijing Institute of Technology (China)

Shouhuan Zhou, North China Research Institute of Electro-optics (China)

Zhongliang Zhu, Southwest Electronic Telecom Technology Research Institute (China) 
Program Committee

Byoungho Lee, Seoul National University (Korea, Republic of)

Liangcai Cao, Tsinghua University (China)

Weibiao Chen, Shanghai Institute of Optics and Fine Mechanics

(China)

Haimei Gong, Shanghai Institute of Technical Physics (China)

Sen Han, University of Shanghai for Science and Technology (China)

Huikai Xie, University of Florida (United States)

John McBride, University of Southampton (United Kingdom)

Yanbiao Liao, Tsinghua University (China)

Dong Liu, Zhejiang University (China)

Jian Liu, Harbin Institute of Technology (China)

Jin Lu, Tianjin Jinhang Institute of Technical Physics (China)

Mircea Guina, Tampere University of Technology (Finland)

Shibin Jiang, AdValue Photonics, Inc. (United States)

Guohai Situ, Shanghai Institute of Optics and Fine Mechanics (China)

Hongbo Sun, Tsinghua University (China)

Yongtian Wang, Beijing Institute of Technology (China)

Yuelin Wang, Shanghai Institute of Microsystem and Information

Technology (China)

Renhe Zhang, Institute of Acoustics (China)

Xuejun Zhang, Changchun Institute of Optics, Fine Mechanics and

Physics (China)

Pu Zhou, National University of Defense Technology (China)

Zhongliang Zhu, Southwest Electronic Telecom Technology Research Institute (China)

\section{Session Chairs}

1 Underwater Optical Detection Technology

Jie Zhang, The First Institute of Oceanography, SOA (China)

Junwu Tang, Pilot National Laboratory for Marine Science and

Technology (China)

2 Ocean Optical Remote Sensing

Xianqiang He, The Second Institute of Oceanography, SOA (China)

Zhongping Li, Xiamen University (China)

3 Underwater Optical Communication and Optical Acoustic Detection

Yixin Yang, Northwestern Polytechnical University (China) 


\section{Introduction}

The International Symposium on Optoelectronic Technology and Application 2018 (OTA 2018) is the annual conference of the Chinese Society for Optical Engineering. It continues to be one of the largest academic and industrial conferences in the field of optical and optoelectronic technology in China. This year's program included academic exchanges, industry exhibitions, and cooperation negotiations together in one event. There were five technical conferences, seven exhibition themes, and 600 technical negotiations. We sincerely hope that this event continues to promote research and development of optoelectronic technology and to enhance international cooperation in the optical and optoelectronic fields.

OTA 2018 was sponsored by The Division of Information and Electronic Engineering of the Chinese Academy of Engineering (China), and The Chinese Society for Optical Engineering (CSOE) (China). The conference was organized by the Chinese Society for Optical Engineering (CSOE) (China), the Photoelectronic Technology Committee, the Chinese Society of Astronautics (China), the Photoelectronic Industrialization Committee, CHIA (China), the Department of Cooperation and Coordination for Industry, Academe, and Research, CHIA (China), and the Science and Technology on Low-light-level Night Vision Laboratory (China). We received more than 759 contributions from more than 15 countries, including the United States, United Kingdom, Germany, France, Spain, Australia, Canada, Mexico, Brazil, Japan, Republic of Korea, Thailand, Singapore, Russian Federation and China. There were more than 400 contributions published in SPIE Proceedings, including 70 contributions from invited speakers. After careful discussion, six keynote speeches were selected and presented by famous scientists from the United States, United Kingdom, Republic of Korea, and China. There were 138 excellent invited talks, 45 from overseas, that reflected first-class level in the field of optics and photonics technology. On behalf of the OTA 2018 Organizing Committee, I would like to express thanks to all the invited speakers and authors for their contributions and support.

Finally, on behalf of the other Co-chairmen and the Organizing Committee, I would like to heartily thank our sponsors and cooperating organizers for all they have done for the conference, and to all of the participants and friends for their interests and efforts in helping us to make the conference a success. Thanks also to the Program Committee for their effective work and valuable advice, especially the Secretariat, and to the staff of SPIE for their tireless efforts and outstanding service preparing and publishing the proceedings.

We hope to see you next year!

\section{Guangjun Zhang}


Proc. of SPIE Vol. 10850 1085001-12 Downloaded From: https://www.spiedigitallibrary.org/conference-proceedings-of-spie on 26 Apr 2023
Terms of Use: https://www.spiedigitallibrary.org/terms-of-use 